УДК 796:338

ББК $75.48+65.9$ (2) -96

ОСОБЕННОСТИ ОПРЕДЕЛЕНИЯ СОЦИАЛЬНОЙ ЭФФЕКТИВНОСТИ ФУНКЦИОНИРОВАНИЯ ОБЪЕКТОВ СПОРТИВНОЙ ИНФРАСТРУКТУРЫ

\author{
В.В. КАРНЕЙЧИК \\ Veronika-KV@tut.by \\ ст. преподаватель кафедры «Экономика строительства» \\ Белорусский национальный технический университет \\ г. Минск, Республика Беларусь
}

Объекты спортивной инфраструктуры являются соииально значимыми, поэтому необходимо оценивать эффективность их функционирования как с экономической точки зрения, так и сочиальной. Для этого изучены и систематизированы подходы $\kappa$ понятию сочииальной эффективности, сформулировано понятие соччиальной эффективности функиионирования объектов спортивной инфраструктуры, обозначены уровни определения сочиальной эффективности, с иелью формирования групп показателей для ее очзенк.

Ключевые слова: эффективность, социальная эффективность, объекты спортивной инфраструктуры, показатели эффективности, социальные результаты, результативность, затраты, экономическая эффективность, оценка эффективности, удовлетворение потребностей.

\title{
FEATURES OF DEFINITION SOCIAL EFFICIENCY OF FUNCTIONING OF OBJECTS OF SPORTS INFRASTRUCTURE
}

\author{
V. V. KARNEICHYK \\ Senior Lecturer of the Department of Construction Economics \\ Belarus National Technical University \\ Minsk, Republic of Belarus
}

The objects of sports infrastructure are socially significant, therefore it is necessary to evaluate the effectiveness of their functioning not only from the economic point of view, but also from the social one. For this purpose, the approaches to the concept of social efficiency were studied and systematized, the notion of social effectiveness of the functioning of sports infrastructure objects was formulated, the levels of determining social efficiency were defined, with the goal of forming groups of indicators for its evaluation.

Keywords: efficiency, social efficiency, sports infrastructure objects, performance indicators, social results, efficiency, costs, economic efficiency, efficiency evaluation, satisfaction of needs.

\section{ВВЕДЕНИЕ}

Понятие «эффективность» имеет два основных значения: в одном случае под данным понятием подразумевают соотношение результата и затрат, в другом - наилучший вариант использования ресурсов. В широком смысле слова эффективность можно характеризовать как комплексную оценку потенциальных и реальных результатов с учетом степени соответствия этих результатов главным целям, использованным ресурсам, а также другим видам количественных и качественных показателей. 
Ученые выделяют экономическую и социальную составляющую эффективности: экономическую, как эффективность стоимостную, социальную - в чьих интересах используются результаты производства [21, с. 26].

С развитием общества в понятие «эффективность» все больше включается социальная составляющая, это связано с тем, что «чем более развито общество, тем выше в нем интересы человека, а не прибыль за счет его эксплуатации» т. е. при планировании производственно-хозяйственной деятельности необходимо, в первую очередь, рассчитать социальные результаты $[1$, с. 8]. Это говорит о том, что уже сама по себе экономическая эффективность обязательно содержит в себе социальный компонент, а экономический результат всегда социально значим. В связи с этим, в мировой практике все чаще применяется концепция социально-экономической эффективности, основанная на признании единства и равенства ее составляющих [21, с. 7].

Возросшее значение проблемы повышения социально-экономической эффективности физкультурно-спортивной сферы объясняется следующими обстоятельствами: вопервых, возросшей ролью этой отрасли в белорусском обществе, во-вторых, возникающей необходимостью в удовлетворении расширяющихся и качественно изменяющихся потребностей населения; в третьих, увеличением влияния этой отрасли на экономику в целом.

Сегодня спортивные объекты должны повышать результаты своей деятельности и одновременно уменьшать все виды затрат. Сущность проблемы повышения эффективности сферы физической культуры и спорта, в частности, функционирования объектов спортивной инфраструктуры, состоит в том, чтобы при относительно меньших затратах бюджетных средств и рациональном использовании ресурсов обеспечить наиболее полное удовлетворение социальных и культурных потребностей населения при сохранении высокого качества оказываемых услуг.

Разграничить понятие социально-экономической эффективности в сфере физической культуры и спорта на социальную и экономическую составляющую достаточно сложно, т. к. в реальной жизни тот или иной конкретный результат деятельности в этой сфере одновременно несет как социальный, так и экономический эффект. Разделение этих двух аспектов довольно условно и имеет значение, главным образом, для научного анализа.

Расширение коммерческой деятельности в этой области повышает не только экономическую эффективность функционирования спортивных объектов, но и социальную, так как благодаря этому, возможно увеличение объема и разнообразия услуг, повышение их качества, соответствующего требованиям потребителей, что способствует привлечению к занятиям большего количества людей. В тоже время, политику ценообразования необходимо проводить с осторожностью, с учетом платежеспособности населения, т. к. коммерциализация услуг, может вызвать обратный процесс в виде оттока занимающихся. Исходя из этого, социальная эффективность в этой отрасли предполагает, что экономические решения принимаются на основе, прежде всего, социальных целей.

\section{РЕЗУЛЬТАТЫ И ИХ ОБСУЖДЕНИЕ}

Перед тем как рассмотреть понятие социальной эффективности функционирования объектов спортивной инфраструктуры необходимо разобраться, что скрывается под определением социальная эффективность. В настоящее время в литературе отсутствует общепринятый единый подход к понятию «социальная эффективность». Это обусловлено различием целей и задач частных методик ее определения, в которых социальная 
эффективность рассматривается с точки зрения различных видов деятельности. Чаще всего, данное понятие имеет разграничение и трактуется в широком и узком смысле.

В широком смысле, рассматривая понятие социальной эффективности, авторы Г. Н. Черкасов, С. С. Абрамов, М. Марков, Г. С. Вечканов и др. сопоставляют социальные результаты с целями, либо представляют ее как отражение результативности общественного процесса в целом. Исследователи К. П. Шишка, М. Л. Леванова, Ф. Шааф и др. делают акцент на степень удовлетворения социальных ожиданий людей, авторы В. Г. Калыгин, Т. С. Костюкова, Е. Е. Румянцева, М. Н. Бродский, А. Б. Берендеева и др. связывают социальную эффективность с затратами материального и нематериального характера.

Кроме того, в публикациях встречаются и такие трактовки социальной эффективности как: благо общества или отдельных групп населения; социально справедливое распределение доходов; результат трудовой деятельности, выраженный в социальных показателях; гармоничное развитие личности; удовлетворение духовных потребностей человека и др.

Анализ существующих точек зрения позволил выделить следующие подходы к категории «социальная эффективность» (таблица 1).

Таблица 1 - Подходы к определению социальной эффективности (разработка автора)

\begin{tabular}{|c|c|c|c|}
\hline $\begin{array}{l}\text { Результативно - } \\
\text { деятельностный }\end{array}$ & Качественный & $\begin{array}{c}\text { Результативно- } \\
\text { затратный } \\
\end{array}$ & Психологический \\
\hline \multicolumn{4}{|c|}{ Краткая характеристика подхода } \\
\hline $\begin{array}{l}\text { Достижение социаль- } \\
\text { ных результатов рас- } \\
\text { сматривается в каче- } \\
\text { стве результативно- } \\
\text { сти, в основном, не } \\
\text { связанной с понятием } \\
\text { затрат }\end{array}$ & $\begin{array}{l}\text { Степень удовлетво- } \\
\text { рения общества и его } \\
\text { членов в определен- } \\
\text { ных потребностях }\end{array}$ & $\begin{array}{l}\text { Отношение социаль- } \\
\text { ного эффекта к затра- } \\
\text { там, обеспечившим } \\
\text { его достижение. } \\
\text { Результативность } \\
\text { связана с понятием } \\
\text { затрат, как матери- } \\
\text { ального, так и нема- } \\
\text { териального харак- } \\
\text { тера }\end{array}$ & $\begin{array}{l}\text { Степень социального } \\
\text { развития личности. } \\
\text { Включает: уровень } \\
\text { нравственности, ин- } \\
\text { теллекта, граждан- } \\
\text { ской активности чело- } \\
\text { века. }\end{array}$ \\
\hline \multicolumn{4}{|c|}{ Представители подхода } \\
\hline $\begin{array}{l}\text { С. С. Абрамов [2], } \\
\text { Г. Н. Черкасов [17], } \\
\text { М. Марков [10], } \\
\text { Г. С. Вечканов [5] }\end{array}$ & $\begin{array}{l}\text { К. П. Шишка [19], } \\
\text { М. Л. Леванова [10], } \\
\text { Ф. Шааф [18] }\end{array}$ & $\begin{array}{l}\text { В. Г. Калыгин [7], } \\
\text { Т. С. Костюкова [8], } \\
\text { Е. Е. Румянцева [12], } \\
\text { А. Б. Берендеева [14], } \\
\text { М. Н. Бродский [4] }\end{array}$ & $\begin{array}{l}\text { Дж. Дьюи [6], } \\
\text { В. Н. Аргунова [3], }\end{array}$ \\
\hline
\end{tabular}

Можно отметить односторонность трактовок, в которых социальная эффективность характеризуются либо материальными показателями, либо социологическими. В этих случаях, данное понятие сводится только к экономической оценке, либо, основываясь лишь на мнении потребителей, становится слишком субъективированным. На наш взгляд, наиболее полными являются те формулировки социальной эффективности, в которых социальная эффективность рассматривается как результативность деятельности, направленная не только на достижение социально-экономических результатов, но и на удовлетворение интересов и потребностей человека, как материальных, так и духовных.

Наиболее полное, на наш взгляд, определение социальной эффективности встречается в экономическом словаре А.И. Архипова [20, с.555], где данное понятие рассматривается как «сложная многофункциональная система связей, опосредующая достижение конечной цели любой формы организации общественного производства - удовлетворение потребностей людей, развитие человека». 
Можно выделить общие характеристики в понимании социальной эффективности в широком смысле. Данное понятие чаще всего: 1) связывают с экономической эффективностью; 2) характеризуется качественной и количественной сторонами; 3) в качестве одного из основных критериев выступает удовлетворенность, которая основывается на ощущении конкретного человека, мнении группы людей и общества в целом.

Понятие «социальная эффективность» в узком смысле слова затрагивает отдельные сферы деятельности, и связана с определенными направлениями экономической и социальной политики государства. Исследователями рассматривается социальная эффективность здравоохранения, которая напрямую связана с качеством медицинского обслуживания и удовлетворением потребностей населения в услугах медицинского назначения [15], социальная эффективность управления организации персоналом [13], природоохранных мероприятий [7] и т. д.

Что касается социальной эффективности функционирования объектов спортивной инфраструктуры, то здесь, наряду с общими чертами рассматриваемого понятия, существуют и свои особенности. Спортивные сооружения, во главе своего функционирования ставят общественные ценности, и, основываясь на них, строят свою работу так, чтобы достичь высоких показателей социальной эффективности. Социальная эффективность функционирования объектов спортивной инфраструктуры находит свое отражение в расширении контингента занимающихся, наиболее полном и широком охвате физкультурно-оздоровительными занятиями различных групп населения.

Трактовка понятия социальная эффективность спортивных объектов встречается в работе С.Н. Зубарева [11], где она характеризуется как «эффективность использования спортивного объекта при удовлетворении потребности профессионального, массового спорта в физкультурно-оздоровительных, спортивных и спортивно-зрелищных услугах».

Изучение разных подходов к определению социальной эффективности позволило предложить расширить данное понятие, т. к. социальная эффективность функционирования спортивных объектов, на наш взгляд, проявляется в привлечении к физкультурнооздоровительным, спортивным занятиям и спортивно-зрелищным мероприятиям максимально возможного количества населения, которое обеспечивается реализацией мер, направленных на удовлетворение соответствующих социально-психологических потребностей и интересов людей, эффект от которых отражается в максимизации социальных и экономических результатов. Такое понимание позволяет по-новому сформулировать рассматриваемое понятие.

Социальная эффективность функционирования спортивных объектов - это создание и поддержание благоприятных условий деятельности спортивных сооружений с целью привлечения к физкультурно-спортивным занятиям наибольшего количества людей; обеспечение всех слоев населения оздоровительными, спортивно-зрелищными услугами; удовлетворение соответствующих социально-психологических потребностей, результат деятельности которых, проявляется в постепенном и долгосрочном эффекте и выражается, главным образом, в снижении негативных явлений, отрицательно влияющих на экономику страны и социума в целом.

Важное значение имеет объективная оценка эффективности в социальных отраслях, в том числе в сфере физической культуры и спорта. Прежде всего, чтобы проанализировать эффективность функционирования объектов спортивной инфраструктуры в социальном плане необходимо использовать систему критериев и показателей, определяющих такую эффективность. Для измерения социальной эффективности чаще всего выделяют следующие показатели: социально-бытовые, социально-демографические, социально-гуманистические, а также обобщающий показатель - уровень социального бла- 
гополучия, под которым понимается состояние субъекта общественного процесса, характеризующееся гармонией между ценностями, интересами, потребностями и возможностями для их удовлетворения [13]. К обобщающим показателям также относят: уровень и качество жизни населения, уровень благосостояния и дифференциации доходов и др. [21, с. 555] В социальной экономике уровень и качество жизни человека и общества в целом являются ведущими ориентирами национального развития.

Для группировки показателей, социальную эффективность предлагается рассматривать на четырех уровнях управления: государственном, отраслевом, отдельной организации, индивидуальном. На государственном уровне социальная эффективность представлена социальной политикой, проводимой государством, которая, в свою очередь, во многом определяет как социальную, так и экономическую сферу. Отраслевой уровень управления затрагивает отдельные сферы деятельности, такие как, здравоохранение, образование, жилищно-коммунальную и др. На уровне отдельной организации рассматривается социальная эффективность функционирования объектов, мероприятий, управления отдельными процессами и др. На индивидуальном уровне изучается степень удовлетворения личных потребностей индивида.

Благодаря этому подходу можно выделить показатели, характеризующие социальную эффективность на разных уровнях управления (таблица 2).

Таблица 2 - Показатели социальной эффективности в зависимости от уровня управления

\begin{tabular}{|c|c|c|c|}
\hline \multicolumn{4}{|c|}{ Уровень определения социальной эффективности } \\
\hline Государственный & Отраслевой & $\begin{array}{c}\text { Отдельной } \\
\text { организации } \\
\end{array}$ & Индивидуальный \\
\hline \multicolumn{4}{|c|}{ Показатели социальной эффективности в зависимости от уровня управления } \\
\hline $\begin{array}{l}\text { 1. Образ жизни и каче- } \\
\text { ство жизни, отражаю- } \\
\text { щиеся в показателях } \\
\text { здоровья людей и про- } \\
\text { должительности жизни } \\
\text { (показатели рождаемо- } \\
\text { сти, смертности, про- } \\
\text { должительности жизни, } \\
\text { временной нетрудоспо- } \\
\text { собности, трудовой ак- } \\
\text { тивности и т. д.). } \\
\text { 2. Уровень жизни (зара- } \\
\text { ботная плата, обеспе- } \\
\text { ченность жильем). } \\
3 . \text { Социально-демогра- } \\
\text { фические (миграция, } \\
\text { рождаемость и др.). } \\
\text { 4. Социально-психоло- } \\
\text { гические (социальное } \\
\text { настроение, уровень } \\
\text { правонарушений, кри- } \\
\text { минализация общества). }\end{array}$ & $\begin{array}{l}\text { Общие показатели: } \\
\text { уровень отраслевой } \\
\text { безработицы, коли- } \\
\text { чество вновь создан- } \\
\text { ных рабочих мест, } \\
\text { уровень заработной } \\
\text { платы и социальной } \\
\text { стабильности в от- } \\
\text { расли, улучшение } \\
\text { условий труда, теку- } \\
\text { честь кадров, уро- } \\
\text { вень развития от- } \\
\text { расли и т. д. } \\
\text { Специфические по- } \\
\text { казатели: } \\
\text { Например, в области } \\
\text { физической } \\
\text { туры: количество за- } \\
\text { нимающихся, спор- } \\
\text { тивные достижения } \\
\text { на международном } \\
\text { уровне и т. д. }\end{array}$ & $\begin{array}{l}\text { Специфические по- } \\
\text { казатели, связанные } \\
\text { с детальными осо- } \\
\text { бенностями конкрет- } \\
\text { ного предприятия, } \\
\text { организации. } \\
\text { Например: объем } \\
\text { предоставленных } \\
\text { услуг организацией, } \\
\text { нормативная и фак- } \\
\text { тическая пропускная } \\
\text { способность объекта } \\
\text { и т. д. }\end{array}$ & $\begin{array}{l}\text { Связаны со степе- } \\
\text { нью удовлетворения } \\
\text { потребностей кон- } \\
\text { кретного человека. } \\
\text { Уровень определя- } \\
\text { ется при помощи со- } \\
\text { циологических } \\
\text { опросов. }\end{array}$ \\
\hline
\end{tabular}

Показатели социальной эффективности на индивидуальном и уровне отдельной организации рассмотрим на примере физкультурно-спортивных объектов. Функционирование спортивных объектов имеет ряд особенностей, которые необходимо учитывать при анализе и оценке эффективности их функционирования.

Социальная эффективность характеризуется количественными и качественными сторонами. Качественная сторона обозначается понятием «критерий», количественная - 
понятием «показатель эффективности». Критерием эффективности является соотношение затрат и результата, а критерием качества - соотношение эффекта и целей, целей и средств их достижения [16].

Применительно к социальным услугам эффективность рассматривается как результативность и является элементом оценки качества услуг. Исходя из этого, систему показателей, характеризующих социальную эффективность функционирования объектов спортивной инфраструктуры, предложено разделить на 2 группы: количественные, измеряемые в натуральных единицах, оценив которые, можно говорить о конкретных результатах, и качественные, отражающие достижения конкретного результата.

Безусловно, универсальных показателей оценки социальной эффективности функционирования спортивных сооружений не существует, т. к. перед каждым объектом стоят свои задачи и ожидаемый от него эффект, но можно выделить и отдельные, как основу для анализа их деятельности.

К количественным показателям предлагается относить: оценку эффективности использования мощностей объекта, через расчет максимальной, плановой и фактической пропускной способности; оценку загрузки объекта по видам услуг и финансированию (платные и бесплатные). К качественным показателям предложено отнести: доступность услуг объекта (пространственная, организационная и стоимостная); спортивные достижения, связанные с подготовкой спортсменов высокого класса; удовлетворенность потребителей разными аспектами предоставляемых услуг: выбором услуг, организацией, стоимостью, качеством проведения занятий, материально-техническим оснащением и санитарно-гигиеническими условиями.

С помощью количественных показателей можно оценить деятельность объекта на основании математических расчетов. В случае, когда измерить эффективность количественно невозможно, следует прибегнуть к качественным показателям, основанным на восприятии потребителя. Качественные показатели можно оценить при помощи балльной шкалы, используя данные, полученные в процессе социологических опросов. В отличие от количественных показателей, оценить качественные показатели социальной эффективности гораздо сложнее, но именно их изучение позволит помочь в решении проблем, выявленных на этапе оценки количественных показателей. Оценка социальной эффективности может быть рассчитана как среднеарифметическое статистической (количественные показатели) и социологической (качественные показатели) оценок.

Проанализировав работу спортивных сооружений по предложенным показателям, можно оценить социальную эффективность их функционирования и, в случае необходимости, определить направления и пути ее повышения.

\section{ВЫВОДЫ}

Исследование различных точек зрения ученых в области социальной эффективности позволило глубоко рассмотреть изучаемое понятие и на основании проведенного сравнительного анализа сформировать четыре подхода к определению социальной эффективности: результативно-деятельностный, качественный, результативно-затратный и психологический. На базе выделенных подходов сформулировано понятие социальной эффективности, относящееся непосредственно к объектам спортивной инфраструктуры, которое позволяет полностью раскрыть ее сущность, заключающееся в охвате физкультурно-оздоровительными и спортивными занятиями различных групп населения, путем создания для этого соответствующих условий, при удовлетворении социально-психологических потребностей людей. 
В работе также выделено четыре уровня управления, для каждого из которых предложены показатели оценки социальной эффективности. На уровне отдельной организации предложена специфическая группа показателей, позволяющая, на наш взгляд, достаточно объективно оценивать эффективность функционирования объектов спортивной инфраструктуры.

\section{СПИСОК ИСПОЛЬЗОВАННЫХ ИСТОЧНИКОВ}

1. Абакаров, М. И. Социально-экономическая эффективность функционирования сферы платных услуг трубоизбыточного региона : автореф. дис. ... док. экон. наук : 08.00.05 / М. И. Абакаров ; МГУ им. М. В. Ломоносова. - М., 2013. - 29 с.

2. Абрамов, С. С. Социально-экономическая эффективность сферы услуг и методы управления ею (на материалах Ростовской области) : автореф. дис. ...канд. соц. наук : 08.00.05 / С. С. Абрамов : ГОО ВПО «Южно-Российский государственный университет экономики и сервиса». - Шахты, 2011. -25 с.

3. Аргунова, В. Н. Социальная справедливость: ценностно-институциональный анализ: монография / В. Н. Аргунова. - Иваново: Иван. Гос. Ун-т., 2004. - 312 с.

4. Бродский, М. Н. Право и экономика: Инвестиционное консультирование / М. Н. Бродский, Г. М. Бродский. - СПб: 1999. - 496 с.

5. Вечканов, Г. С. Современная экономическая энциклопедия / Г. С. Вечканов. СПб., Издательство «Лань», 2002. - 880 с.

6. Дьюи, Дж. Демократия и образование: Пер. с англ. / Дж. Дьюи. - М.: Педагогика-Пресс, 2000. - 384 с.

7. Калыгин, В. Г. Промышленная экология: учебник для студ. учреждения высшее образования. - 5-е изд., испр. доп. / В. Г. Калыгин. - М.: Издат. центр: «Академия», 2017. -365 c.

8. Костюкова, Т. С. Социальная эффективность услуг государства населению : автореф. дис. ...канд. соц. наук : 22.00.03. / Т. С. Костюкова ; ВПО «Тюменский гос. университет». - Тюмень, 2013. - 23 с.

9. Леванова, М. Л. Социально-экономическая эффективность сферы услуг (политико-экономический аспект) : автореферат дис. ... канд. экон. наук : 08.00.01 / М. Л. Леванова ; Гос. фин. акад. - Москва, 1992. - 24 с.

10. Марков, М. Технология и эффективность социального управления: перев. с болгарского / Марко Марков ; под ред и с предис. Т. В. Керимовой. - М.: Прогресс, 1982. $-267 \mathrm{c}$.

11. Оценка эффективности использования спортивных объектов: метод. Пособие / гл. ред. С. Н. Зубарев. - Москва, 2008. - 113 с.

12. Румянцева, Е. Е. Новая экономическая энциклопедия: 4-е изд. / Е. Е. Румянцева. - М.: ИНФРА-М., 2016. - 882 с.

13. Самков, К. Н. Методология и методика оценки социальной эффективности деятельности местной администрации в социальной сфере / К. Н. Самков // Научный вестник Уральской академии государственной службы. - 2009. - № 1 (6).

14. Социальные аспекты инновационного развития региона. Социальные аспекты инновационного развития региона / Иван. гос. ун-т ; науч. ред. О. А. Хасбулатова, А. Б. Берендеева. - Науч. изд . - Иваново : ИвГУ, 2013 . - 331 с.

15. Сурмач, М. Ю. Социальная эффективность как основной показатель деятельности здравоохранения по формированию здоровья молодежи / М. Ю. Сурмач // Охрана 
здоровья: проблемы организации, управления и уровни ответственности: интернет-конференция, 16 апреля - 15 июня 2007. [Электронный ресурс]. - Режим доступа: https:// www.ecsocman.edu.ru/db/msg/307359.html. - Дата доступа: .10.09.2018.

16. Терзиев, В. К. Социальная эффективность как мера деятельности в социуме / В. К. Терзиев, Е. Н. Стоянов // Международный научный журнал «Инновационная наука». - 2016. - № 3 - С. 225-234.

17. Черкасов, Г. Н. Бригадная организация труда: состояние и перспективы / Г. Н. Черкасов. - М.: Профиздат, 1986. - С. 123-126.

18. Шааф, Ф. Спортивный маркетинг / перев. с англ. Ф. Шааф. - М.: Инф.изд. дом «Филилъ», 1998. - 464 с.

19. Шишка, К. П. Социально-экономическая эффективность деятельности учреждений социального обслуживания : автореф. дис. ... канд. экон. наук : 08.00.05 / К. П. Шишка ; Всерос. центр уровня жизни. - Москва, 2003. - 30 с.

20. Экономический словарь / А. И. Архипов [и др.]; отв. Ред. А. И. Архипов. - 2-е изд., перераб. и доп. - Москва: Проспект, 2016. - 672 с.

21. Эффективность в международной экономике / В. В. Почекина, В. В. Ковальчук; под науч. Ред. П. Г. Никитенко; Институт экономики НАН Беларуси. - Минск: Право и экономика, 2007. - 390 с.

\section{REFERENCES}

1. Abakarov, M. I. Social'no-ehkonomicheskaya ehffektivnost' funkcionirova-niya sfery platnyh uslug truboizbytochnogo regiona : avtoref. dis. ... dok. ehkon. nauk : 08.00.05 / M. I. Abakarov ; MGU im. M. V. Lomonosova. - M., 2013. - 29 s.

2. Abramov, S. S. Social'no-ehkonomicheskaya ehffektivnost' sfery uslug i me-tody upravleniya eyu (na materialah Rostovskoj oblasti) : avtoref. dis. ...kand. soc. nauk : 08.00.05 / S. S. Abramov : GOO VPO «Yuzhno-Rossijskij gosudarstvennyj uni-versitet ehkonomiki i servisa». - SHahty, 2011. $-25 \mathrm{~s}$.

3. Argunova, V. N. Social'naya spravedlivost': cennostno-institucional'nyj analiz: monografiya / V. N. Argunova. - Ivanovo: Ivan. Gos. Un-t., 2004. - 312 s.

4. Brodskij, M. N. Pravo i ehkonomika: Investicionnoe konsul'tirovanie / M. N. Brodskij, G. M. Brodskij. - SPb: 1999. - 496 s.

5. Vechkanov, G. S. Sovremennaya ehkonomicheskaya ehnciklopediya / G. S. Vechkanov. - SPb., Izdatel'stvo «Lan'», 2002. - $880 \mathrm{~s}$.

6. D'yui, Dzh. Demokratiya i obrazovanie: Per. s angl. / Dzh. D'yui. - M.: Pedago-gikaPress, 2000. $-384 \mathrm{~s}$.

7. Kalygin, V. G. Promyshlennaya ehkologiya: uchebnik dlya stud. uchrezhdeniya vysshee obrazovaniya. - 5-e izd., ispr. dop. / V. G. Kalygin. - M.: Izdat. centr: «Akademiya», 2017. $-365 \mathrm{~s}$.

8. Kostyukova, T. S. Social'naya ehffektivnost' uslug gosudarstva naseleniyu : avtoref. dis. ...kand. soc. nauk : 22.00.03. / T. S. Kostyukova ; VPO «Tyumenskij gos. universitet». Tyumen', 2013. - $23 \mathrm{~s}$.

9. Levanova, M. L. Social'no-ehkonomicheskaya ehffektivnost' sfery uslug (po-litikoehkonomicheskij aspekt) : avtoreferat dis. ... kand. ehkon. nauk : 08.00.01 / M. L. Levanova ; Gos. fin. akad. - Moskva, 1992. - 24 s.

10. Markov, M. Tekhnologiya i ehffektivnost' social'nogo upravleniya: perev. S bolgarskogo / Marko Markov ; pod red i s predis. T. V. Kerimovoj. - M.: Progress, 1982. - 267 s.

11. Ocenka ehffektivnosti ispol'zovaniya sportivnyh ob"ektov: metod. Poso-bie / gl. red. S. N. Zubarev. - Moskva, 2008. - 113 s. 
12. Rumyanceva, E. E. Novaya ehkonomicheskaya ehnciklopediya: 4-e izd. / E. E. Rumyan-ceva. - M.: INFRA-M., 2016. - 882 s.

13. Samkov, K. N. Metodologiya i metodika ocenki social'noj ehffektivnosti deyatel'nosti mestnoj administracii v social'noj sfere / K. N. Samkov // Nauchnyj vestnik Ural'skoj akademii gosudarstvennoj sluzhby. - 2009. - № 1 (6).

14. Social'nye aspekty innovacionnogo razvitiya regiona. Social'nye as-pekty innovacionnogo razvitiya regiona / Ivan. gos. un-t ; nauch. red. O. A. Hasbulato-va, A. B. Berendeeva. - Nauch. izd . - Ivanovo : IvGU, 2013 . - 331 s.

15. Surmach, M. Yu. Social'naya ehffektivnost' kak osnovnoj pokazatel' deya-tel'nosti zdravoohraneniya po formirovaniyu zdorov'ya molodezhi / M. Yu. Surmach // Ohrana zdorov'ya: problemy organizacii, upravleniya i urovni otvetstvennosti: in-ternet-konferenciya, 16 aprelya - 15 iyunya 2007. [Ehlektronnyj resurs]. - Rezhim dostu-pa: https://www.ecsoc man.edu.ru/db/msg/307359.html. - Data dostupa: .10.09.2018.

16. Terziev, V. K. Social'naya ehffektivnost' kak mera deyatel'nosti v sociume / V. K. Terziev, E. N. Stoyanov // Mezhdunarodnyj nauchnyj zhurnal «Innovacionnaya nauka». 2016. - № 3 - S. 225-234.

17. Cherkasov, G. N. Brigadnaya organizaciya truda: sostoyanie i perspektivy / G. N. CHerkasov. - M.: Profizdat, 1986. - S. 123-126.

18. Shaaf, F. Sportivnyj marketing / perev. s angl. F. SHaaf. - M.: Inf.izd. dom «Filil"», 1998. - $464 \mathrm{~s}$.

19. Shishka, K. P. Social'no-ehkonomicheskaya ehffektivnost' deyatel'nosti uchrezhdenij social'nogo obsluzhivaniya : avtoref. dis. ... kand. ehkon. nauk : 08.00 .05 / K. P. SHishka ; Vseros. centr urovnya zhizni. - Moskva, 2003. - 30 s.

20. Ehkonomicheskij slovar' / A. I. Arhipov [i dr.]; otv. Red. A. I. Arhipov. - 2-e izd., pererab. i dop. - Moskva: Prospekt, 2016. - 672 s.

21. Ehffektivnost' v mezhdunarodnoj ehkonomike / V. V. Pochekina, V. V. Koval'chuk; pod nauch. Red. P. G. Nikitenko; Institut ehkonomiki NAN Belarusi. - Minsk: Pravo I ehkonomika, 2007. - $390 \mathrm{~s}$.

Статья поступила в редакциюю 12 сентября 2018 года 